\title{
Normative Morphometry of Adult Sudanese Mandible: A 3D Computerized Tomography Based Study
}

\author{
Khalid Mohammed Ahmed ${ }^{1}$, Caroline Edward Ayad ${ }^{1}$ \\ ${ }^{1}$ Sudan University of Science And Technology, Collage of Medical Radiological Science-Khartoum -Sudan.
}

\begin{abstract}
:
Mandible being largest and strongest bone of skull, having various morphological features may show changes with reference to age, gender and race. The aims of this study were to characterize the mandible and to find out if there is age /gender related differences as well as to establish a local reference for the Sudanese mandible measurements.

In this descriptive study, the facial computerized tomography scans were obtained from 160 subjects (92males and 68 females). The population of the study was categorized in six ages (15to24, 25to34, 35to44, 45to54, 55 to64 and ages $>65$ years old). Volume rendering three-dimensional reconstruction technique was used. Specific parts of the mandible were measured and the data were analyzed using SPSS program version 16. Results showed that the Bicondylar breadth, Bigonial breadth, Mandibular body length and Mandibular symphysis height, differ significantly between the two genders at $p \leq 0.000$. Correlation coefficient showed a significant relation between the patient's age and Bi condylar breadth $\left(R^{2}=0.360\right)$. A new established equation and a local reference for Sudanese Bicondylar breadth measurement were established. This study presents a new morphologic indicator of age in the human mandible for Sudanese.
\end{abstract}

Keywords: Age; $3 D$ Computerized Tomography; Mandible

\section{Introduction}

The mandible is the strongest bone of facial skeleton and the best preserved after death. [1].The sex differences are well marked in the bony pelvis and skull. Sex determination from a given bone of an individual is of great value for medical jurist who often gives expert opinion from the available skeletal remains. Skull is the most dimorphic and easily sexed portion of skeleton after pelvis. [1] As a component of the skull, mandible shares the character. The study of identification of sex for a single bone is important medico legally and anthropologically. If the mandible alone is available; besides gender, age and race also can be determined. Mandible, maxilla and teeth are best preserved parts of the body after death. The mandible has been extensively in ancient studied (Martin 1936, Morant 1936, Stewart 1954 [2,3,4]. Their work was based on biometric study, mathematical methods. Studies took into account that males differ than females, Diwan (1987) [5] Facial aging is a dynamic process involving bony structures. The age related changes of bony morphology are not well defined.[6] Previous researches focused on changes in soft tissue and skin with aging but changes in bones and facial skeleton significantly affected the aging face [7] Any kind of changes in the mandibular projection, width, or height can affect the overall aesthetics.[8] Reshaping of the face with ageing is the result of volume changes and loss of support.[9]

The ability of CT imaging to display fine bone details, makes it an ideal modality for lesions that involve bone. The three-dimensional CT has been applied to trauma and craniofacial reconstructive surgery, and has been used for treatment of congenital and acquired deformities.[10 ] Early literature analyzing facial bone aging, focused on the orbit and mid face. It was believed that the bony face continued to grow with age, particularly with the increase in facial width and depth. In contrast, many recent studies suggest that the bone aging of the facial bone is a process primarily of contraction and morphologic changes. [7, 8, 11]In a study which was carried out by Shaw et al. on 3D CT images, it was revealed that there were no significant changes in bigonial width and ramus breadth across ages in both genders. Ramus height, mandibular body height and mandibular body length decreased with age for both genders and mandibular angle increased in both genders across ages.[7]

Raising the knowledge of mandible changes with age has been highly essential due to an increasing demand for facial treatment. The aim of this study is to characterize the mandible and to find out the norms and to study if there is age and/ or gender related deference. To the best of our knowledge no studies have been published in the open literature regarding the characteristics of the mandible in Sudanese population using 3DCT.Therefore this study was designed to establish a local reference for the Sudanese norms of the mandible compartments measurements. 


\section{Equipment:-}

\section{Materials and Methods}

The equipment required is CT Toshiba Aquilion(64slices) and three dimensional reconstruction system with parameters is used as below: $\mathrm{Kv}=120, \mathrm{~mA}=300$, Time $=0.75 \mathrm{sec}, \mathrm{mAs}=225$,Slice thickness=3mm$5 \mathrm{~mm}$.

\section{Methods of data measurement}

This is a descriptive analytical study that deals with scanning patients head (brain and facial structures).The study selected 160 patients (males and females) with CT (64slices). Axial projection was applied with brain protocols as well as sagittal views for facial protocols. All of these protocols used two dimensional as localizer and Digital Imaging and Communications in Medicine (DICOM) files were rendered into threedimensional reconstruction using Anatomize Invivo5 software.The mandible was measured by selecting, right ramus height, left ramus breadth, bicondylar breadth, bigonial breadth, Mandibular body length, mandibular symphysis height, Corpus width and left petrous bone length. All of these following mandibular land marks are measured as distance between two points in each of them as below:

Bicondylar breadth: Distance between most lateral points on the two condyles.

Bigonial breadth: Distance between right and left gonia (outer point on either side of the lower jaw at which the jawbone angles upward).

Mandibular body length: Distance between most anterior margin of the chin to a line connecting right and left gonions.

Mandibular symphysis height: Distance between infradentale(apex of the septum between the mandibular central incisors) tognathion (most inferior point of the mandible in the midline).

Corpus width: Width measured at the region at the mental foramen..

Ramus height: Distance between highest point of mandibular condyle to gonion.

Ramus breadth: Minimum width of mandibular ramus from anterior to posterior.

Petrous bone length: Distance between lateral border of petrous bone and base of the skull

\section{Study Population}

The study population was composed of both genders presenting to the CT unit of Military Hospital in Khartoum during the period from December 2013 to June 2016.The sample size consisted of 160 patientswith different age, sex (92males and 68 females )The radiographs that were clinically diagnosed as normal mandible were included. Any abnormality of mandible for example: fractures, infection, tumors and other mandible diseases were excludes

\section{Technique:}

The patients were positioned in supine on the CT examination table and head is rested on head holder while removing all metallic and jewelry, straps and pillow were used to help in maintaining the correct positioning, the scan started from base of the skull and end inferior to mental protuberance as well as image were produced in axial projection. Three dimensional volume rendering technique was applied to reconstruct the image data of patients (analytical software) uses several types of reconstruction algorithm with different planes

\section{Ethical consideration:}

-No identification or individual details were published.

-No information or patient details were disclosed or used for reasons other than the study.

\section{Results}

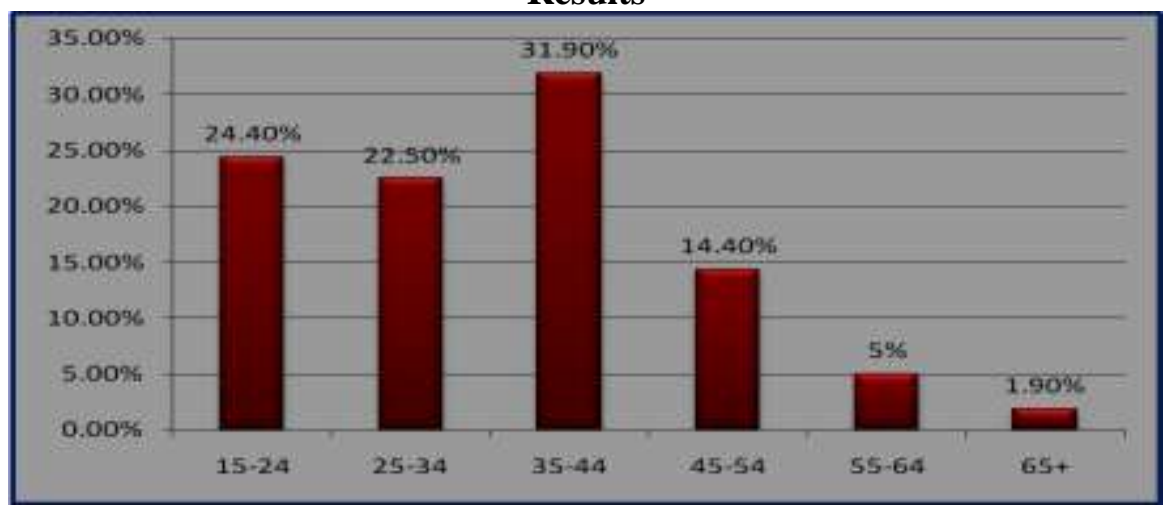


Figure (1): Distribution of the sample according to age classes, presented in percentages.

Table (1): Descriptive statistics of the mandible compartments mean, standard deviation, maximum and minimum values.

\begin{tabular}{|l|l|l|l|l|l|l|l|}
\hline & $\begin{array}{l}\text { Bicondylar } \\
\text { breadth* }\end{array}$ & $\begin{array}{l}\text { Bigonial } \\
\text { breadth* }\end{array}$ & $\begin{array}{l}\text { Mandibular } \\
\text { body } \\
\text { length* }\end{array}$ & $\begin{array}{l}\text { Mandibular } \\
\text { symphysis } \\
\text { height* }\end{array}$ & $\begin{array}{l}\text { Corpus } \\
\text { width* }\end{array}$ & $\begin{array}{l}\text { Right } \\
\text { Ramus } \\
\text { height } \\
*\end{array}$ & $\begin{array}{l}\text { Left } \\
\text { Ramus } \\
\text { breadth } \\
*\end{array}$ \\
\hline *Mean & 112.9 & 93.8 & 85.6 & 34.9 & 8.9 & 60.9 & 33.5 \\
\hline Std. Deviation & 7.6 & 9.9 & 7.5 & 1.9 & 6.6 & 42.6 & 2.3 \\
\hline Minimum & 98.0 & 79.0 & 74.9 & 31.1 & 7.0 & 46.0 & 28.5 \\
\hline Maximum & 131.9 & 116.0 & 106.1 & 43.1 & 92.0 & 594.0 & 43.2 \\
\hline
\end{tabular}

*Measurements were taken in $(\mathbf{m m})$

Table (2): Independent samples test shows the mandible compartment in both genders and $\mathrm{p}$ value

\begin{tabular}{|c|c|c|c|c|c|}
\hline & Gender & $\mathbf{N}$ & Mean & Std. Deviation & P-value \\
\hline \multirow[t]{2}{*}{ Bicondylar breadth } & Male & 92 & 115.24 & 7.013 & \multirow[t]{2}{*}{0.000} \\
\hline & Female & 68 & 109.81 & 7.35 & \\
\hline \multirow{2}{*}{ Bigonial breadth } & Male & 92 & 99.87 & 8.35 & \multirow[t]{2}{*}{0.000} \\
\hline & Female & 68 & 85.63 & 4.58 & \\
\hline \multirow[t]{2}{*}{ Mandibular body length } & Male & 92 & 90.14 & 6.20 & \multirow[t]{2}{*}{0.000} \\
\hline & Female & 68 & 79.40 & 3.86 & \\
\hline \multirow{2}{*}{$\begin{array}{l}\text { Mandibular } \\
\text { height }\end{array}$} & Male & 92 & 34.30 & 1.98 & \multirow[t]{2}{*}{0.000} \\
\hline & Female & 68 & 35.76 & 1.60 & \\
\hline \multirow[t]{2}{*}{ Corpus width } & Male & 92 & 9.57 & 8.71 & \multirow[t]{2}{*}{0.126} \\
\hline & Female & 68 & 7.94 & .48 & \\
\hline \multirow[t]{2}{*}{ Right Ramus height } & Male & 92 & 62.62 & 56.21 & \multirow[t]{2}{*}{0.545} \\
\hline & Female & 68 & 58.48 & 1.43 & \\
\hline \multirow[t]{2}{*}{ Left Ramus breadth } & Male & 92 & 33.31 & 2.84 & \multirow[t]{2}{*}{0.187} \\
\hline & Female & 68 & 33.79 & .99 & \\
\hline
\end{tabular}

Table (3): Independent samples test shows the mandible compartment classified according to different age

\begin{tabular}{|c|c|c|c|c|c|c|c|}
\hline $\begin{array}{l}\text { Anatomical } \\
\text { and age class }\end{array}$ & Structure & $\mathbf{N}$ & Mean & Std. Deviation & Minimum & Maximum & p-value \\
\hline \multirow{7}{*}{$\begin{array}{l}\text { Bicondylar } \\
\text { breadth }\end{array}$} & $15-24$ & 39 & 103.8410 & 6.75927 & 98.00 & 117.60 & \multirow[t]{7}{*}{0.000} \\
\hline & $25-34$ & 36 & 114.2861 & 8.61109 & 102.00 & 131.90 & \\
\hline & $35-44$ & 51 & 116.3059 & 2.65024 & 110.90 & 120.00 & \\
\hline & $45-54$ & 23 & 116.0130 & 1.77157 & 113.30 & 118.40 & \\
\hline & $55-64$ & 8 & 118.1375 & 2.13404 & 115.50 & 120.00 & \\
\hline & $>65$ & 3 & 120.2667 & .05774 & 120.20 & 120.30 & \\
\hline & Total & 160 & 112.9369 & 7.62723 & 98.00 & 131.90 & \\
\hline \multirow{7}{*}{$\begin{array}{l}\text { Bigonial } \\
\text { breadth }\end{array}$} & $15-24$ & 39 & 88.2667 & 10.90192 & 79.00 & 116.00 & \multirow[t]{7}{*}{0.000} \\
\hline & $25-34$ & 36 & 99.3222 & 12.69457 & 81.30 & 115.30 & \\
\hline & $35-44$ & 51 & 94.9176 & 5.37206 & 87.70 & 103.10 & \\
\hline & $45-54$ & 23 & 93.6652 & 7.69702 & 85.80 & 105.20 & \\
\hline & $55-64$ & 8 & 87.4875 & 1.22058 & 86.20 & 89.80 & \\
\hline & $>65$ & 3 & 99.5000 & .20000 & 99.30 & 99.70 & \\
\hline & Total & 160 & 93.8219 & 9.93239 & 79.00 & 116.00 & \\
\hline \multirow{7}{*}{$\begin{array}{l}\text { Mandibular } \\
\text { body length }\end{array}$} & $15-24$ & 39 & 84.1487 & 10.08007 & 74.90 & 106.10 & \multirow[t]{7}{*}{0.005} \\
\hline & $25-34$ & 36 & 88.6222 & 7.71689 & 77.20 & 105.00 & \\
\hline & $35-44$ & 51 & 86.5314 & 4.68651 & 77.50 & 94.30 & \\
\hline & $45-54$ & 23 & 83.2522 & 6.90987 & 77.10 & 95.50 & \\
\hline & $55-64$ & 8 & 79.1250 & .44320 & 78.60 & 79.70 & \\
\hline & $>65$ & 3 & 86.6333 & .11547 & 86.50 & 86.70 & \\
\hline & Total & 160 & 85.5813 & 7.53018 & 74.90 & 106.10 & \\
\hline \multirow{7}{*}{$\begin{array}{l}\text { Mandibular } \\
\text { symphysis } \\
\text { height }\end{array}$} & $15-24$ & 39 & 34.9179 & 1.85527 & 31.80 & 37.00 & \multirow[t]{7}{*}{0.122} \\
\hline & $25-34$ & 36 & 35.4139 & 2.73236 & 31.10 & 43.10 & \\
\hline & $35-44$ & 51 & 34.3490 & 1.42610 & 32.10 & 36.70 & \\
\hline & $45-54$ & 23 & 35.3087 & 1.82680 & 32.30 & 37.50 & \\
\hline & $55-64$ & 8 & 34.9375 & 1.32011 & 33.60 & 37.50 & \\
\hline & $>65$ & 3 & 36.1333 & .15275 & 36.00 & 36.30 & \\
\hline & Total & 160 & 34.9281 & 1.96309 & 31.10 & 43.10 & \\
\hline \multirow{7}{*}{$\begin{array}{l}\text { Corpus } \\
\text { width }\end{array}$} & $15-24$ & 39 & 10.3231 & 13.43280 & 7.50 & 92.00 & \multirow[t]{7}{*}{0.768} \\
\hline & $25-34$ & 36 & 8.7944 & .82978 & 7.50 & 10.50 & \\
\hline & $35-44$ & 51 & 8.2118 & .64549 & 7.00 & 9.50 & \\
\hline & $45-54$ & 23 & 8.3435 & .50975 & 7.40 & 9.10 & \\
\hline & $55-64$ & 8 & 8.2750 & .38822 & 7.80 & 8.80 & \\
\hline & $>65$ & 3 & 8.4000 & .10000 & 8.30 & 8.50 & \\
\hline & Total & 160 & 8.8831 & 6.64601 & 7.00 & 92.00 & \\
\hline
\end{tabular}




\begin{tabular}{|c|c|c|c|c|c|c|c|}
\hline $\begin{array}{l}\text { Anatomical } \\
\text { and age class }\end{array}$ & Structure & $\mathrm{N}$ & Mean & Std. Deviation & Minimum & Maximum & \\
\hline \multirow{7}{*}{$\begin{array}{l}\text { Right } \\
\text { Ramus } \\
\text { height }\end{array}$} & $15-24$ & 39 & 70.3872 & 86.28324 & 46.00 & 594.00 & \multirow[t]{7}{*}{0.766} \\
\hline & $25-34$ & 36 & 57.9417 & 3.18159 & 53.40 & 68.70 & \\
\hline & $35-44$ & 51 & 58.1490 & 2.12559 & 52.90 & 63.80 & \\
\hline & $45-54$ & 23 & 56.4870 & 2.34100 & 51.70 & 60.00 & \\
\hline & $55-64$ & 8 & 58.2625 & .26693 & 57.70 & 58.50 & \\
\hline & $>65$ & 3 & 58.9000 & 10000 & 58.80 & 59.00 & \\
\hline & Total & 160 & 60.8663 & 42.58401 & 46.00 & 594.00 & \\
\hline \multirow{7}{*}{$\begin{array}{l}\text { Left Ramus } \\
\text { breadth }\end{array}$} & $15-24$ & 39 & 32.5590 & 2.99848 & 28.50 & 38.50 & \multirow[t]{7}{*}{0.001} \\
\hline & $25-34$ & 36 & 34.8306 & 1.87095 & 32.90 & 43.20 & \\
\hline & $35-44$ & 51 & 33.5118 & 1.93366 & 31.30 & 37.90 & \\
\hline & $45-54$ & 23 & 33.4957 & 1.40178 & 31.90 & 35.70 & \\
\hline & $55-64$ & 8 & 32.6875 & 1.34104 & 31.80 & 35.90 & \\
\hline & $>65$ & 3 & 32.7333 & .05774 & 32.70 & 32.80 & \\
\hline & Total & 160 & 33.5181 & 2.26015 & 28.50 & 43.20 & \\
\hline
\end{tabular}

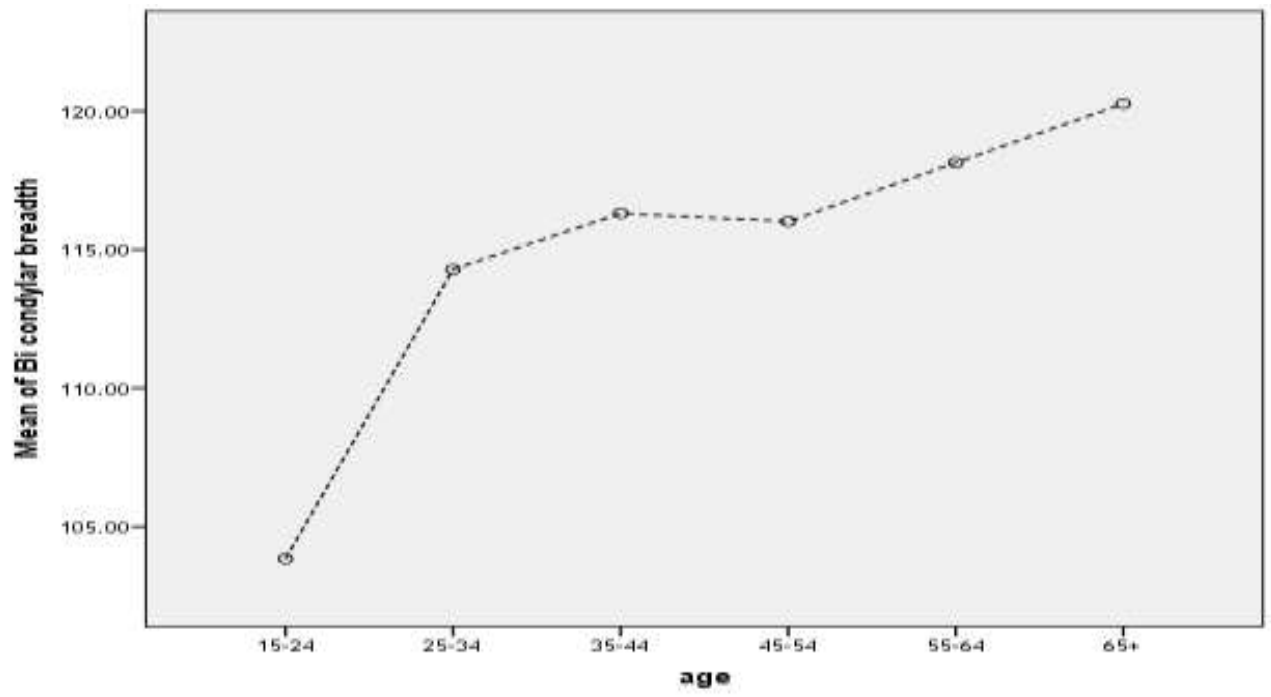

Figure (2): Correlation coefficient shows the relation between the patient's age and Bi condylar breadth $\left(\mathrm{R}^{2}=0.360\right)$

Table (4): The New established equations For Sudanese considering the Bi condylar breadth and patients ages .

\begin{tabular}{|c|c|c|c|c|}
\hline \multicolumn{5}{|c|}{ Coefficients } \\
\hline \multirow{2}{*}{\multicolumn{2}{|c|}{ Model }} & Unstandardized Coefficients & \multirow[t]{2}{*}{$\mathrm{t}$} & \multirow[t]{2}{*}{ Sig. } \\
\hline & & $\mathrm{B}$ & & \\
\hline & (Constant) & 99.845 & 67.933 & .000 \\
\hline & Age & .371 & 9.433 & .000 \\
\hline
\end{tabular}

Dependent Variable: Bi condylar breadth

The New established equations For Sudanese are as follows

Bi condylar breadth $=4.99 .84+($ Age $X 0.371)$.

\section{Discussion}

The mandible is the largest and hardest facial bone and retains its shape better than other bones in the forensic and physical anthropologic field. The mandible can be used to distinguish among ethnic groups and between genders.[12]

We used the three dimensional CT images, since these images allow for more accuracy in the obtained measurements compared with the previous studies. [13] Distribution of the sample according to age classes was presented in percentages (Figure1) and the most frequently presented age group was the group of age between 35-44years old. The mean measurements of the Sudanese mandible components were presented in (Table1)

The current study showed that the measurements in both male and female subjects were statistically differ in bicondylar breadth, bigonial breadth,and mandibular body length. The males have greater measurements than females and the difference was significant at $\mathrm{p} \leq 0.000$. The mandibular symphysis height was statistically greater in females than males (Table 2), similar findings was mentioned by Roshanak et al; 2013. [13] In each three studies; the mean of bigonial width in men was greater than in women. [13, 14, 15] 
In another study run by Pecora et al., 2008 [16] it was found that women had a downward and backward rotation in mandible but men had a forward rotation in mandible. Hence, the increase in mandibular angle in females is more than in men.[16] this may be the cause of the difference between the two genders .

Studies mentioned that mandibular ramus can differentiate between genders, as the stages of mandibular development, growth rates, and duration are distinctly different in both genders. In addition, masticatory forces exerted are different for males and females, which influences the shape of the mandibular ramus.[12] Study done by Steyn et al [17] showed bigonial breadth was the most dimorphic of the measurements taken .No significant difference was observed in mandibular angle in sex determination in the young Lebanese population aged between 17 and 26 years . [18]

Various parameters have been used for sexing the mandible. Studies done by Loth et al, on their nonmetric examination on South African sub adult samples claimed that, shape differences in the symphyseal region and anterior body of the mandible can be used to predict sex with above $80 \%$ accuracy. In a blind test of that technique, however, Scheuer showed that when applied to different population samples, sex classification accuracy declined considerably to $64 \%$. The most accurate single indicators among cranial methods were the robustness of the mandible with accuracy of 70.93\% [19]

Many variables showed significant differences which includes: bicondylar breadth, gonial angle and minimum ramus breadth according to study done by Kharoshah et al.[20] In Sudanese population, the mean bi bicondylar breadth, bigonial bridth mandibular body length and left ramus breadth changed significantly with increasing age (Table3). Comparing with other populations; one study showed that, the mean of bigonial width did not change significantly with increasing age. [13] In a similar study by Shaw et al. [15] on 3D CT images, also the mean of bigonial width did not change significantly with increasing age. Sudanese measurements were differ from other populations.

Results of Roshanak et al [13] and Shaw et al [15]were different from that of Pessa et al. [14] Pessa et al. evaluated the frontal radiographs and reported that there was an increase in mandible width and height with increasing age. The current results mentioned that mandibular body length, left ramus breadth were significantly increased in measurements as the age increases at $p \leq 0.005$ and $p \leq 0.001$.The changes in measurements may be due to the fact that some areas continued to grow faster than other areas. The measurements starts to increased during the ages starting from 15-24 years, 25-34years then decreased after the age of 45-54years and 55-64 years .Similar study has mentioned that the changes were in maturity period [14]

Correlation coefficient shows the relation between the patient's age and bi condylar breadth $\left(\mathrm{R}^{2}=0.360\right)$ the contribution of the age to do changes in bi condylar breath is $36 \%$. As the age increases the bicondylar breadth will also be increased significantly at $\mathrm{p} \leq 0.000$. These were presented in (Table4) and (Figure2).

\section{Conclusion}

We can predict the bi condyler width for Sudanese if their ages were known. A new equation was established in order to standardize a local reference or measurements for Sudanese mandibles. This study presents a new morphologic indicator of age in the human mandible.

\section{References}

[1]. T.Jayachandra Pillai1, T.Sobha Devi2, C.K.lakshmi Devi Studies on Human Mandibles IOSR Journal of Dental and Medical Sciences (IOSR-JDMS) Volume 13, Issue 1 Ver. II (Jan. 2014), PP 08-15

[2]. Martin,E.S. A study of an Egyptian series of Mandibles with special reference to Mathematical methods of sexing.1936 Biometrica.28:119-178

[3]. Morant,G. A Biometric study of Human Mandible. Biometrica.1936, Vol.28.p.84-112

[4]. Stewart.T.D Adult American Negro Skeleton Sexed by Inspection(94\%). Evaluation of Evidence from theSkeleton.In:Gradwohi,REH(ed),Legalmedicine,Mosby,St.Louis,1954,p.407-50

[5]. Diwan,C.V.,Fakhruddin,S.andShroff,A.G.MedicalCollage,Aurangabad.SexingtheMandiblebyMultivariateAnalysis.1987JournalofA nAnatomicalSocietyofIndiaVol.36,No.1,April1987,p.42.

[6]. Richard MJ, MorrisC, Deen BF, Gray L, Woodward JA. Analysis of the Anatomic Changes of the aging facial Skeleton Using Computer-assisted Tomography. Ophthal Plast Reconstr Surg 2009: 25(5): 382-3862.

[7]. Shaw RB Jr, Katzel EB, Koltz PF, Kahn DM, Girotto JA, Langstein HN. Aging of the Mandible and its Aesthetic Implications. Plast Reconstr Surg. 2010; 125(1): 332-342.

[8]. Shaw RB Jr, Katzel EB, Koltz PF, et al. Aging of the facial Skeleton: Aesthetic Implications and Rejuvenation Strategies. Plast Reconstr Surg 2011; 127(1):374-83.

[9]. Levine RA, Garza JR, Wang PT, et al. Adult facial growth: applications to aesthetic surgery. AestheticPlast Surg 2003 ;27(4):265268.

[10]. White Sc, Pharoah MJ. Oral Radiology Principles and interpretation. 6th ed. St. louis: Mosby Elsevier; 2009. pp. 209-211

[11]. Kahn DM, Shaw RB Jr. Aging of the bony orbit: A three dimensional Computed Tomographic Study. Aesthetic Surg J 2008; 28(3) 258-264.

[12]. James D. Raj and Sindhu Ramesh ,Sexual Dimorphism in Mandibular Ramus of South Indian Population Antrocom Online Journal of Anthropology 2013, vol. 9. n. $2-253-258$

[13]. Roshanak Ghaffari 1, Abolfath Hosseinzade2, Hossein Zarabi3, Marzieh Kazemi Mandibular Dimensional Changes With Aging In Three Dimensional Computed Tomographic Study In 21 To 50 Year Old Men And Women journal Of Dentomaxillofacial Radiology, Pathology And Surgery Vol 2, No 1, 2013,7-12 
[14]. Pessa JE, Slice DE, Hanz KR, et al. Aging and the Shape of the Mandible. PlastReconstr Surg. 2008; 121(1): 196-200.

[15]. Shaw RB Jr, Katzel EB, Koltz PF, Kahn DM, Girotto JA, Langstein HN. Aging of the Mandible and its Aesthetic Implications. Plast Reconstr Surg. 2010; 125(1): 332-342

[16]. Pecora NG, Baccetti T, Mcnamara JA. The aging Craniofacial Complex: A Longitudinal Cephalometric Study from late adolescence to late adulthood. Am J orthod Dentofacial Orthop 2008; 134(4): 496-505

[17]. Steyn M, Ican MY. Sexual dimorphism in the crania and mandibles of South African whites. Forensic Sci Int. 1998 Nov 30; $98(1-$ 2): $9-16$.

[18]. Ayoub F, Rizk A, Yehya M, Cassia A, Chartouni S, Atiyeh F, Majzoub Z. Sexual dimorphism of mandibular angle in a Lebanese sample. J. Forensic Leg Med. 2009 Apr; 16(3): 121-4.

[19]. Duric, M.; Rakocevic, Z. and Donic, D. (2005): "The reliability of sex determination of skeletons from forensic context in the Balkans". Forensic Sci. Int., 147: 159- 164.

[20]. Kharoshah MA, Al Madani OM, Galeb SS, Zaki MK, Abdel Fattah YA. Sexual dimorphism of the mandible in a modern Egyptian population. J Forensic Leg Med May 2010; 17(4): 213e5. 